\title{
Hoe kan medische kennis het beste beklijven?
}

\author{
H.P.A. Boshuizen
}

\section{Samenvatting}

Het doen beklijven van kennis is een belangrijke uitkomst van onderwijsinspanningen. Beheersing in de leerfase, rijke representatie in het geheugen en actieve bewerking bevorderen het beklijven. Activeren van aanwezige kennis helpt om nieuwe kennis te verwerven. Belangrijk voor geheugenprestaties zijn: kennisnetwerken, encapsulaties (concepten die patiëntbevindingen verbinden met klinische en biomedische kennis), ziektescripts (het ontstaan, het onderliggende proces, en de verschijnselen en symptomen van de aandoening), en actiekennis (diagnostische procedures, behandeling).

Kennisnetwerken ontstaan door inspanningen om een tekst te begrijpen. Toepassing van kennis leidt tot begrip en legt verbindingen tussen concepten. Encapsulatievorming verloopt op vergelijkbare wijze. Ziektescripts en actiekennis zijn gebonden aan ervaring met patiënten.

De vereiste mate van beheersing (raamplan) bepaalt of voor een bepaald ziektebeeld alleen een kennisnetwerk vereist is of dat daarnaast ook kennis van ziektescripts en actiekennis vereist zijn. Kennis van de basisvakken is belangrijk voor de samenhang in het kennisbestand.

Studenten gebruiken oppervlakkige (uit het hoofd leren) en dieptestrategieën (begrip en verbinding met aanwezige kennis) om kennis te onthouden. Opleiders gebruiken nut, timing en toepassing. Nut bevordert motivatie, timing verbinding van kennis uit verschillende domeinen en toepassing de vorming van ziektescripts en het heractiveren van wegzakkende kennis. (Boshuizen HPA. Hoe kan medische kennis het beste beklijven? Tijdschrift voor Medisch Onderwijs 2006;25(6):273-278.)

\section{Inleiding}

"Het onderwijs dat aan faculteiten geneeskunde wordt gegeven, heeft als hoofddoel binnen een tijdsbestek van zes jaar relatieve beginners te veranderen in bekwame beroepsbeoefenaren. Daartoe volgen studenten colleges, komen ze bij elkaar in kleine groepen, krijgen ze speciale vaardigheidstrainingsprogramma's en zijn er de co-assistentschappen. Toch zijn opleiders niet altijd even gelukkig met de uitkomsten van hun inspanningen. Een van de klachten is dat studenten misschien wel kennis hebben van onderwerp $\mathrm{X}$ of $\mathrm{Y}$, maar dat ze daar geen blijk van geven in de situaties waarin die kennis moet worden toegepast. Verder zouden studenten niet in staat zijn klinische problemen op te lossen, met name niet in praktische settings. Misschien kunnen ze dat nog wel in beschermde, gesimuleerde situaties, maar wanneer ze geconfronteerd worden met echte patiënten en echte problemen lijken ze hun competentie soms geheel of gedeeltelijk te verliezen. Door de jaren heen hebben dit soort observaties geïnspireerd tot een aantal belangrijke onderzoeksprojecten. ${ }^{1-2}$ Ook de introductie van nieuwe onderwijsmethoden in de geneeskunde die bedoeld zijn om het klinische redeneren in de geneeskunde te verbeteren vloeit hieruit voort. 3 "

Zo begon het artikel dat ik in 1993 samen met Henk Schmidt ${ }^{4}$ voor dit tijd- 
schrift schreef. In de tussentijd is er veel, maar tegelijkertijd ook weinig veranderd in het medisch onderwijs. Wat er veranderd is, is de samenwerking tussen opleidingen en de competentiegerichtheid die door de curricula heen schemert. Ook hebben veranderende opvattingen over de inrichting van de gezondheidszorg hun invloed op de wijze waarop tegen opleiden wordt aangekeken. ${ }^{5}$ Wat gebleven is, is o.a. de vraag hoe we de uitkomsten van onze onderwijsinspanningen kunnen optimaliseren. In dit artikel is deze vraag toegespitst op het doen beklijven van de verworven kennis. Ik zal proberen te antwoorden aan de hand van de volgende deelonderwerpen:

1. Beklijven en herinneren.

2. Wat moet er beklijven?

3. Hoe kunnen we beklijven bevorderen? Ik doe dat met behulp van een aantal psychologische wetten en empirische bevindingen op het terrein van geheugen- en expertiseontwikkeling in de geneeskunde en eindig met een aantal aanbevelingen.

\section{Beklijven en herinneren}

Psychologisch gezien kunnen geheugenprocessen opgedeeld worden in een aantal stadia: de encodering, de opslag en het herinneren van wat eerder is opgeslagen. Hebben we het over beklijven, dan bedoelen we meestal opslag en herinneren. Om permanent opgeslagen te kunnen worden, is een periode van consolidatie nodig. Een hersenschudding of een elektroshock kunnen voorkomen dat die consolidatie optreedt met als gevolg het bekende 'gat' van een paar minuten of seconden in het geheugen voordat een trauma plaatsvond. Ook andere fysiologische processen zijn van invloed op de werking van het geheugen. Bijvoorbeeld een hoog niveau van corticosteroïden bemoeilijkt verschillende leer- en geheugenprocessen. ${ }^{6}$ Aan deze processen wordt echter niet in de eerste plaats gedacht wanneer we het hebben over het verbeteren van de resultaten van onderwijsinspanningen, alhoewel ook deze bevindingen onderwijskundige implicaties hebben: voorkom hoofdtrauma, maar voorkom vooral dat studenten onder langdurige stress komen te staan, want dat beïnvloedt hun leren in negatieve zin.

Permanente opslag wordt in hoge mate bepaald door de mate van beheersing in de leerfase. Een mooie demonstratie daarvan werd geleverd door Bahrick die de term 'permafrost' introduceerde. Hij onderzocht hoeveel er na soms heel lange intervallen (tot wel 50 jaar) nog overbleef van het Spaans dat leerlingen op de middelbare school hadden geleerd, maar waarmee ze daarna niet veel meer hadden gedaan. Na een periode van drie tot zes jaar waarin duidelijk verval optrad, bleek er een 'restbestand' over te blijven van zo'n $60 \%$ dat verder weinig door de tand des tijds werd beïnvloed. De omvang van dat restbestand werd in de eerste plaats beïnvloed door de mate van beheersing die ooit bereikt was. Hoe meer en hoe beter er was geleerd, hoe meer er overbleef. ${ }^{7}$ Deze constatering is hoopgevend voor diegenen die reeds lang zijn afgestudeerd. Echter, voor de inrichting van het onderwijs betekent ze dat we strijden tegen een proces van continu verval. Het betekent ook dat een zesjes-mentaliteit studenten tot in lengte van jaren zal blijven achtervolgen.

Naast de opslag is ook het ophalen van groot belang bij geheugenprestaties. Herinneren is voor een groot deel (her)activeren en (re)constructie, en soms ook herleren. Hoe goed een geheugenelement kan worden teruggevonden, hangt af van de rijkheid van de aanwezige representatie in het geheugen (het resultaat van de encodering, de eerste fase) en van de mate waarin de 'zoeksleutel' op die representa- 
tie past. De aard van die zoeksleutel wordt op haar beurt weer bepaald door twee dingen: 1) elementen uit de situatie waarin een arts of student zich bevindt en 2) een signalement van het gezochte, van het doel waarvoor de te zoeken kennis nodig is.

Het zal duidelijk zijn dat hoe beter de zoeksleutel en de representatie op elkaar passen, hoe beter de herinnering zal zijn. Perfecte overlap leidt uiteraard tot de beste prestaties. Perfecte overlap is echter niet nodig en zal ook niet vaak optreden. Op één na het beste resultaat ontstaat wanneer er sprake is van een rijke, gevarieerde representatie. Hoe gevarieerder die representatie is, des te groter de kans dat een zoeksleutel resultaat zal hebben.

\section{Encodering en representatie}

Hoe rijker en gedifferentieerder de representatie, des te groter de kans op succes bij geheugenprocessen. Hoe ontstaan dergelijke rijke representaties? Niet in één keer. Bij het vormen van nieuwe representaties wordt het menselijk geheugen beperkt door een aantal eigenschappen van dat geheugen. Ten eerste kunnen zintuiglijke indrukken maar korte tijd zonder verdere bewerking en interpretatie in de daarbij behorende buffers blijven 'hangen'. Ten tweede heeft het werkgeheugen waarin de interpretatieprocessen plaatsvinden een beperkte capaciteit. Zonder actieve bewerking of herhaling zal nieuwe informatie daaruit snel verdwijnen. Voeg daarbij de tijd die nodig is voor consolidatie en het zal duidelijk zijn dat de eerste representaties nogal mager zullen zijn. Het geheugen heeft echter een andere eigenschap die het verrijken van die eerste representaties vereenvoudigt. Aanwezige kennis helpt namelijk om nieuwe kennis te verwerven, dat wil zeggen, wanneer die aanwezige kennis in de verwerkingsfase kan worden geactiveerd. En dat is weer afhankelijk van de fit tussen de nieuwe en al aanwezige kennis.

In ons eigen onderzoek waaraan onder andere promovendi als Margje van de Wiel, Eugène Custers, Remy Rikers, Pie Hobus en Mette Hofstra meewerkten, bleek dat over de jaren die iemand nodig heeft om zijn of haar medische kennis op te bouwen en te verfijnen, een aantal processen optraden die we interpreteerden als essentieel om tot een geheugenprestatie op professioneel niveau te kunnen komen. Dat laatste wil zeggen dat het kennisbestand dat na een aantal jaren is ontstaan iemand in staat stelt om met voldoende zekerheid, binnen acceptabele tijd, tot kwalitatief goede inschattingen, beslissingen en acties te komen. De volgende processen spelen volgens ons een essentiële rol:

1. De vorming van goed samenhangende kennisnetwerken die met name functioneren om gevonden verschijnselen te kunnen verklaren, en die eerder in het leerproces helpen om verbanden tussen verschijnselen te kunnen zien.

2. De vorming van concepten die een verbindende rol spelen tussen het gedetailleerde verklarende niveau en het niveau van de klinische empirie. Voorbeelden van dit soort concepten, encapsulaties genoemd, zijn forward en backward failure, micro-embolieën, en dergelijke. In expertredeneringen nemen ze de plaats in van de detailconcepten die eronder liggen. Tegelijkertijd leggen ze verband tussen de patiëntbevindingen en klinische en biomedische kennis. Zowel in de communicatie met collega's als in eigen redeneringen spelen ze een essentiële rol.

3. De vorming van ziektescripts. Ziektescripts beschrijven de manifestatie, het ontstaan en het verloop van (families van) aandoeningen. Ze hebben een 
vaste verschijningsvorm: factoren die aanleiding geven tot of juist bescherming geven voor een bepaalde aandoening (enabling conditions), het onderliggende proces (fault), en de verschijnselen en symptomen die er een gevolg van zijn (consequences). Ziektescripts zijn gekoppeld aan actiekennis: diagnostische procedures, vuistregels voor verwijzing, patiëntmanagement en behandeling. ${ }^{4}$

Voor alle drie deze kennisvormen geldt dat ze kunnen verschillen in rijkheid en mate van detaillering. Rijke netwerken bevatten meer concepten en veel, meer gedifferentieerde verbindingen. Encapsulaties verschillen in de omvang van de netwerken die ze omvatten en in de hoeveelheid klinische manifestaties die ze incorporeren. De ziektescripts tenslotte verschillen in de mate van verfijning van met name de enabling conditions en consequences, en de actiekoppelingen. Voor alle drie de processen geldt dat meer expertise samengaat met een verbetering op al deze aspecten.

Willen we deze bevindingen echter vertalen naar aanbevelingen voor het onderwijs, dan moeten we kijken naar welke activiteiten tot deze processen hebben geleid. Het vormen van samenhangende netwerken begint wanneer een student probeert een tekst of voordracht op dit terrein te begrijpen. Het begrip wordt verdiept en de verbindingen tussen de concepten worden bijgesteld wanneer deze kennis vervolgens wordt gebruikt om verschijnselen te verklaren. Daarnaast wordt het netwerk op deze manier gekalibreerd op de klinische werkelijkheid. Ook dit proces kost tijd en inspanning. In uitlegprotocollen van een casus over levercirrose was bijvoorbeeld heel goed te zien dat jongerejaars studenten de betreffende casus maar vanuit één perspectief konden beschouwen, bijvoorbeeld het patho-ana- tomische, terwijl ouderejaars studenten en experts tegelijkertijd ook de gevolgen op hormonaal gebied en op het gebied van detoxificatie in ogenschouw konden nemen. De overige kennis hadden die jongerejaars wel, maar deze was niet zodanig georganiseerd dat ze die kennis in één moeite mee konden nemen. In ander onderzoek zagen we echter dat wanneer je een student vervolgens een casus met vergelijkbare onderliggende problematiek geeft, hij in staat is om dan een stapje verder te gaan ${ }^{8}$ en er een tweede perspectief bij te betrekken.

Ook de vorming van encapsulaties lijkt een gevolg van een dergelijk proces te zijn. Eerst verwerven studenten een concept, maar dit heeft nog geen speciale status in het netwerk. Pas later gaat het die encapsulerende rol in uitleg en communicatie spelen. De verfijning van ziektescripts daarentegen is vooral een gevolg van ervaring met patiënten met die aandoening. Onderzoek laat zien dat de ontwikkeling van de enabling conditionscomponent langzamer verloopt dan die van de consequences.9-10 De koppeling aan de actiekennis is ook duidelijk ervaringsgebonden. ${ }^{11-12}$

Veel hangt dus af van de kwaliteit van het leerproces dat op zijn beurt weer beïnvloed wordt door de kwaliteit van de aanwezige kennis.

\section{Welke kennis moet er beklijven?}

In tegenstelling tot de vorige vraag is dit in de eerste plaats een vraag hoe het curriculum moet worden opgebouwd. Oftewel: hoe zorg je ervoor dat het juiste wordt geleerd? Uit voorgaande is al gebleken dat de aard van de representaties niet arbitrair is, en dat ook een zekere mate van rijkheid en detaillering bereikt moet worden. Kennis van ziektebeelden is typisch in ziektescripts gerepresenteerd. Het onderscheid dat in het Raamplan 
2001 artsopleiding 13 wordt gemaakt tussen aandoeningen waarvan de basisarts gehoord moet hebben, aandoeningen die hij/zij in de decursus moet kunnen opnemen en aandoeningen die zelfstandig gediagnosticeerd en behandeld moeten kunnen worden, suggereert dat van de laatste twee typen aandoeningen volledige ziektescripts noodzakelijk zijn, maar dat de basisarts alleen van de laatste soort ook de bijbehorende actiekennis moet hebben. Voor de 'van-gehoord-hebben' aandoeningen is het voldoende kennis te hebben die gerepresenteerd is in een netwerk.

De basiskennis wordt in het raamplan niet op deze manier uitgewerkt. Deze zou ten dienste moeten staan van het begrijpen van de kennis van aandoeningen. In het vorige is al gebleken dat deze kennis van groot belang is bij nieuw en verder leren van aandoeningen: het creëert de samenhang in het kennisbestand die noodzakelijk is om te leren en om verval tegen te gaan.

\section{Hoe kunnen we beklijven bevorde- ren?}

Studenten kennen een aantal methoden om het beklijven van hun kennis te garanderen: oppervlakkige en dieptestrategieën. ${ }^{14}$ In termen van het voorafgaande zijn de oppervlakkige methoden er vooral op gericht de eigenschap van het geheugen te pareren dat elementen die niet worden gebruikt in het opslagproces slecht worden opgeslagen. Door uittreksels te maken en die uit het hoofd te leren en losse onderdelen te stampen wordt alleen de essentiële informatie hopelijk lang genoeg in het geheugen actief gehouden om tot een voldoende houdbare representatie te komen. De diepe verwerkingsstrategieën zijn er juist op gericht de nieuwe kennis te begrijpen en te verbinden met reeds aanwezige kennis. De oppervlakkige methode lijkt effectief en efficiënt, maar het resultaat zal in veel gevallen slechts duren tot het komende examen. De diepe methoden leiden tot beter samenhangende en rijkere representaties.

Opleidingen en opleiders hebben meer middelen in handen om het leerresultaat langer stand te doen houden: nut, timing, integratie en toepassing. Nut van de kennis ligt ook ten grondslag aan de indeling in het raamplan. Nut, naast interesse, is een belangrijke factor voor motivatie, die op haar beurt weer bepaalt hoeveel energie een student in de studie zal steken. Timing en integratie bepalen of kennis van verschillende domeinen met elkaar verbonden zal raken en dus weer de rijkheid en samenhang van de representatie. Een goede timing voorkomt dat de kennis die met andere kennis moet worden geïntegreerd al is weggezakt. Toepassing tenslotte op levensechte problemen, die ook een zo levensecht mogelijk gedrag van de student vereisen, bevordert op twee manieren het beklijven van de kennis: de omzetting van netwerkkennis naar of de verrijking van ziektescripts en hun toepassing is een vorm van oefenen die er toe leidt dat wegzakkende kennis geheractiveerd wordt. Zo mogelijk zal er met meerdere manifestaties van dezelfde aandoening moeten worden geoefend.

\section{Tenslotte}

We hebben het tot nu toe alleen over kennis gehad. Vaardigheden volgen deels een ander traject. Over het verlies van vaardigheden is beduidend minder bekend dan over het vergeten van kennis. Eén van de dingen die wel bekend zijn, is dat de koppeling aan diagnostiek snel kan verdwijnen. ${ }^{15}$ Dit pleit ervoor om het verwerven van diagnostische en therapeutische vaardigheden zoveel mogelijk in het verlengde van het opbouwen van ziektescripts plaats te laten vinden. 


\section{Literatuur}

1. Barrows HS, Feightner JW, Neufeld VR, Norman GR. An analysis of the clinical method of medical students and physicians. Hamilton, Ontario: McMaster University; 1978.

2. Elstein AS, Shulman LS, Sprafka SA. Medïcal problern solving. An analysis of clinical reasoning. Cambridge, Massachusettes: Harvard University Press; 1978.

3. Norman GR, Schmidt HO. The psychological basis of problem-based learning: a review of the evidence. Acad Med 1992;67:557-65.

4. Boshuizen HPA, Schmidt HG. Kennisontwikkeling en onderwijs in de geneeskunde: een subtiel evenwicht. Bulletin Medisch Onderwijs 1993;12:98-109.

5. Arnold A. Geen zorg meer zonder onderzoek en onderwijs [inaugerele rede]. Amsterdam: Vrije Universiteit; 2005.

6. Brunner R, Schaefer D, Hess K, Parzer P, Resch F, Schwab S. Effect of corticosteroids on short-term and long-term memory. Neurology 2005;64:335-7.

7. Bahrick HP. Semantic memory content in permastore: fifty years of memory for Spanish learned in school. J Exp Psychol Gen 1984;113(1):1-29.

8. Boshuizen HPA, Wiel MWJ van de. Multiple representations in medicine: how students struggle with it. In: Someren MW van, Reimann P, Boshuizen HPA, Jong T de, editors. Learning with multiple representations. Amsterdam: Elsevier; 1998.

9. Hobus PPM, Hofstra ML, Boshuizen HPA, Schmidt, HG. De context van de klacht als diagnosticum. Huisarts Wet 1988;31:261-3.

10. Custers EJFM, Boshuizen HPA, Schmidt, HG. The influence of medical expertise, case typicality and illness script component on case processing and disease probability estimates. Mem Cognit 1996;24(3):384-99.
11. Wimmers PF. Developing clinical compentece [dissertatie]. Rotterdam: Erasmus Universiteit; 2006.

12. Schaik P van, Flynn D, Wersch A van, Douglas A, Cann P. Influence of illness script components and medical practice on medical decision making. J Exp Psychol Appl 2005;11(3):187-99.

13. Metz JCM, Verbeek-Weel AMM, Huisjes HJ. Raamplan 2001 artsopleiding: bijgestelde eindtermen van de artsopleiding. Nijmegen: Universitair Publicatiebureau Katholieke Universiteit Nijmegen; 2001. Beschikbaar op: http://www.vsnu.nl/ web/p?DOWNLOAD. raamplan_2001_artsopleiding\&id $=46766$.

14. Vermunt JD, Vermetten YJ. Patterns in student learning: relationships between learning strategies, conceptions of learning, and learning orientations. Educational Psychology Review 2004;16(4):359-84.

15. Patrick J. Training. Research and practice. London: Academic Press; 1992.

De auteur:

Mw. prof. dr. H.P.A. Boshuizen is decaan onderwijskunde/onderwijstechnologie aan de Open Universiteit Nederland te Heerlen.

Correspondentieadres:

Mw. prof. dr. H.P.A. Boshuizen, Open Universiteit Nederland, Onderwijstechnologisch Expertise Centrum, Postbus 2960, 6401 DL Heerlen, tel.: 045-5762180, els.boshuizen@ou.nl.

Belangenconflict: geen gemeld.

Financiële ondersteuning: geen gemeld.

\section{Summary}

Retention of knowledge in memory is an important educational outcome. Mastery during the acquisition stage, rich representations in memory and active manipulation of knowledge promote retention. Activation of prior knowledge facilitates acquisition of new knowledge. Important for memory processes are: knowledge networks, encapsulation of knowledge (concepts linking patient findings to clinical and biomedical knowledge), illness scripts (comprising aetiology, underlying processes, and signs and symptoms), and action knowledge (diagnostic procedures, treatment).

Knowledge networks originate from efforts to understand texts. Using knowledge promotes understanding and linking of concepts. Encapsulation follows a similar path. Illness scripts and action knowledge require experience with patients.

The required level of mastery (Blueprint) determines whether a knowledge network suffices or whether illness scripts and action knowledge should be present as well. Basic science knowledge promotes coherence of knowledge networks.

Students use surface (memorisation) and deep learning strategies (understanding and linking to prior knowledge) to acquire knowledge. Teachers use usefulness, timing and application. Usefulness promotes motivation, timing enables connections between knowledge from different domains and application develops illness scripts and reactivates declining knowledge. (Boshuizen HPA. How to promote retention of medical knowledge? Dutch Journal of Medical Education 2006;25(6):273-278.) 